\title{
Risk-score based strategy to minimize antibiotic exposure in children with sickle cell disease and fever
}

\author{
Elena María Rincón-López ${ }^{1,2,7}$ (10 - María Luisa Navarro Gómez ${ }^{1,3} \cdot$ Teresa Hernández-Sampelayo Matos ${ }^{1,3}$. \\ David Aguilera-Alonso ${ }^{1}$. Eva Dueñas Moreno ${ }^{4}$. José María Bellón Cano ${ }^{4}$. Jesús Saavedra-Lozano ${ }^{1,3}$. \\ María del Mar Santos Sebastián ${ }^{1} \cdot$ Marina García Morín ${ }^{5}$. Cristina Beléndez Bieler ${ }^{5}$. Jorge Lorente Romero ${ }^{6}$. \\ Elena Cela de Julián ${ }^{3,5}$. on behalf of F-DREP Study Group
}

Received: 26 July 2021 / Accepted: 16 September 2021 / Published online: 1 October 2021

(c) Springer-Verlag GmbH Germany, part of Springer Nature 2021

\begin{abstract}
Severe bacterial infections (SBI) have become less frequent in children with sickle cell disease (SCD) in the last decades. However, because of their potential risk of SBI, they usually receive empirical therapy with broad-spectrum antibiotics when they develop fever and are hospitalized in many cases. We performed a prospective study including 79 SCD patients with fever [median age 4.1 (1.7-7.5) years, $78.5 \%$ males; 17 of the episodes were diagnosed with SBI and 4 of them were confirmed] and developed a risk score for the prediction of SBI. The optimal score included CRP $>3 \mathrm{mg} / \mathrm{dl}$, IL- $6>125 \mathrm{pg} /$ $\mathrm{ml}$ and hypoxemia, with an AUC of $0.91(0.83-0.96)$ for the prediction of confirmed SBI and $0.86(0.77-0.93)$ for possible SBI. We classified the patients in 3 groups: low, intermediate and high risk of SBI. Our risk-score-based management proposal could help to safely minimize antibiotic treatments and hospital admissions in children with SCD at low risk of SBI.
\end{abstract}

Keywords Sickle cell disease $\cdot$ Children $\cdot$ Infection $\cdot$ Acute chest syndrome $\cdot$ Risk score $\cdot$ Antibiotics

The members of the F-DREP Study Group are listed in Acknowledgements.

Elena María Rincón-López

elenarinconlopez@hotmail.com

1 Department of Pediatrics, Pediatric Infectious Diseases Unit, Hospital General Universitario Gregorio Marañón, Instituto de Investigación Sanitaria Gregorio Marañón (IiSGM), Madrid, Spain

$2 \mathrm{PhD}$ Program in Medicine, Universidad Complutense de Madrid, Madrid, Spain

3 Universidad Complutense de Madrid, Madrid, Spain

4 Instituto de Investigación Sanitaria Gregorio Marañón (IiSGM), Madrid, Spain

5 Department of Pediatrics. Pediatric Hematology and Oncology Unit, Hospital General Universitario Gregorio Marañón, Madrid, Spain

6 Department of Pediatrics. Pediatric Emergency Unit, Hospital General Universitario Gregorio Marañón, Madrid, Spain

7 Servicio de PediatríaSección Enfermedades Infecciosas, Hospital Materno-Infantil Gregorio Marañón, c/ O'Donnell, 48-50, 28009 Madrid, Spain

\begin{tabular}{ll}
\multicolumn{2}{l}{ Abbreviations } \\
SBI & Severe bacterial infection \\
SCD & Sickle cell disease \\
CRP & C-reactive protein \\
IL-6 & Interleukin 6 \\
CSBI & Confirmed severe bacterial infection \\
PSBI & Possible severe bacterial infection \\
ACS & Acute chest syndrome \\
ROC & Receiver operating characteristic \\
PPV & Positive predictive value \\
NPV & Negative predictive value \\
PR & Prevalence rate \\
UTI & Urinary tract infection \\
CVC & Central venous catheter
\end{tabular}

\section{Introduction}

The incidence of bacteremia and other severe bacterial infections (SBI) in children with sickle cell disease (SCD) has decreased in recent years in high-income countries, mainly due to the introduction of preventive measures such as vaccination and antibiotic prophylaxis [1-4]. However, because of their potential risk of SBI, they usually receive empirical 
therapy with broad-spectrum antibiotics when they develop fever, and are hospitalized in many cases [4]. Frequent use of broad-spectrum antibiotics entails complications such as potential side effects or driving resistance in bacteria and increasing health care cost. The aims of this study were to develop a risk score for the prediction of SBI in children with SCD and fever and to propose an alternative strategy of management according to the risk group of each patient. This proposal could help to safely minimize the use of broad-spectrum antibiotics and hospital admissions in those patients at low risk of SBI.

\section{Materials and methods}

We performed a prospective study, from June 2015 to June 2018, including children with SCD and fever at the Hospital General Universitario Gregorio Marañón in Madrid, a reference center for patients with SCD in Spain. Exclusion criteria included age older than 18 years, hematopoietic stem cell transplantation, incomplete diagnostic tests and patients whose parents or legal guardians did not sign the informed consent form. The study received approval from the Institutional Review Board.

The following diagnostic tests were performed on all study participants (regardless of the symptoms of each patient) upon arrival at the hospital or at the time of onset of fever if it appeared during the first $24 \mathrm{~h}$ of hospitalization: blood tests [complete blood count, biochemistry, C reactive protein (CRP), procalcitonin and 10 proinflammatory cytokines], blood cultures and nasopharyngeal samples for viral detection by a multiplex-PCR assay. The lack of any of the previous studies would be considered an exclusion criterion from the study. Other diagnostic tests and the patients' management were performed according to national guidelines [4]. Confirmed SBI (CSBI) was defined as a severe infection with the identification of a microorganism in a normally sterile site and possible SBI (PSBI) as a clinical syndrome compatible with SBI but not microbiologically confirmed. For the purposes of this study, pneumonia without a bacterial confirmation and acute chest syndrome (ACS) were considered PSBI. Hereinafter, SBI will be used to refer to CSBI and PSBI together. More detailed data about study setting and definitions are described in Supplemental data.

\section{Statistical analysis}

Continuous variables were compared with $T$ test or Mann-Whitney $U$ test, whereas $\chi^{2}$ test or Fisher's exact test were used for categorical variables. A $p$ value $<0.05$ was considered significant. A multivariate logistic regression predictive model was used to design a risk score, including significant variables from the univariate analyses and from previous studies $[4,5]$ and transforming quantitative variables into binary variables, with the most sensitive cutoffs. The best predictive model was chosen using the Akaike information criterion. Coefficients from the multivariate regression model were converted into integer "points" to create the score. Receiver operating characteristic (ROC) curves were generated. Sensitivity, specificity, positive predictive values (VPP) and negative predictive values (NPV) were calculated for different cut-off values and the last two also according to various possible prevalence rates (PR) of SBI. Predictive margins were used to report probabilities with 95\% confidence intervals of CSBI and PSBI according to the risk score.

\section{Results}

Seventy-nine febrile episodes were included in the study (flow diagram in Fig. 1). Median age of the patients was 4.1 (interquartile range 1.7-7.5) years and 78.5\% of the episodes occurred in males. Most children had been diagnosed by newborn screening $(91.1 \%)$, were appropriately immunized $(88.6 \%)$ and were receiving penicillin prophylaxis $(98.7 \%)$.

Seventeen episodes were diagnosed with SBI: 4 CSBI [3.2\%; 2 catheter-related bacteremia caused by Staphylococcus aureus and Enterobacter cloacae, respectively, one Streptococcus pneumoniae bacteremic pneumonia (serotype $9 \mathrm{~N}$ ) and one Escherichia coli urinary tract infection (UTI)] and 13 PSBI [16.5\%; 12 pneumonia/ACS and one bacterial-viral coinfection (E. coli UTI and influenza B)]. A virus was detected in 41 (51.9\%) of the respiratory samples, being influenza ( $\mathrm{A}$ or B) and rhinovirus the more frequently detected viruses, in $23.3 \%$ and $20.9 \%$ of the cases, respectively. Patients with a viral detection in respiratory simples had a significantly higher frequency of upper respiratory

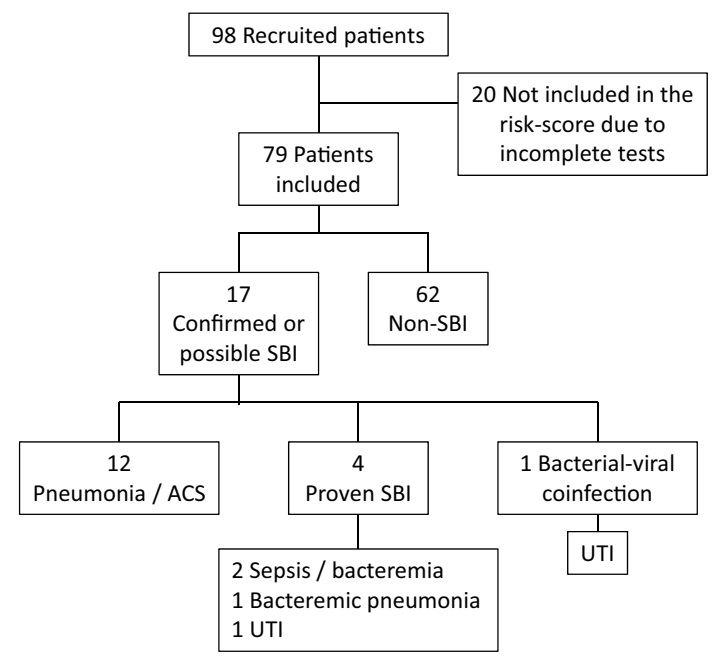

Fig. 1 Flow diagram 
symptoms than those with CSBI or those without a proven infection ( $80.5 \%$ vs $50 \%$ vs $42.4 \%$; $p=0.003$ ). Baseline characteristics of patients, clinical and laboratory parameters during the febrile episode and comparisons between patients with and without SBI are summarized in Table 1. Most of the patients were treated as inpatients $(81 \%)$ and received at least one dose of antibiotic (96.2\%). Three patients (3.8\%) needed PICU admission ( 2 of them for exchange transfusion, diagnosed with ACS, and 1 with an acute splenic sequestration, with ages of 4.1, 3.6 and 1.4 years, respectively) and no patient died. Patients with SBI presented more frequently with hypoxemia, had significantly higher inflammatory parameters and longer duration of fever and hospitalization.

The variables included in the initial predictive model were hypoxemia $<92 \%$, hemodynamic instability, central venous catheter $(\mathrm{CVC})$, initial white blood count $>15 \times / \mathrm{L}$, neutrophils $>10 \times / \mathrm{L}, \mathrm{CRP}>3 \mathrm{mg} / \mathrm{dl}$, procalcitonin $>0.6 \mathrm{ng} /$ $\mathrm{ml}$ and IL- $6>125 \mathrm{pg} / \mathrm{ml}$. The best predictive model included CRP $>3 \mathrm{mg} / \mathrm{dl}$ ( 2 points), IL- $6>125 \mathrm{pg} / \mathrm{ml}$ ( 1 point) and hypoxemia (1 point). The area under the ROC curve for this model was 0.91 (95\% CI 0.83-0.96) for the prediction of CSBI and 0.86 (0.77-0.93) for PSBI. Table 2 shows the performance of the predictive model for CSBI and PSBI according to different cut-off points, with the best sensitivity and NPV for $\geq 1$ point and the best specificity and $P P V \geq 3$ point. Based on these cut-off points, the individual risk of a patient can be divided into 3 groups: low risk ( 0 points), moderate risk (1-2 points) and high risk ( $3-4$ points). The individual risk score of patients in our cohort and the proportion of SBI in each group are also detailed in Table 2 . The probability of SBI according to the risk score is shown in Fig. 2. Our management proposal, according to the risk group of each patient, is described in Fig. 3.

\section{Discussion}

In this prospective study, we propose a risk-score based strategy of management for children with SCD and fever, according to their risk group of SBI, with the final goal of minimizing antibiotic exposure in those patients at low risk. To avoid the possibility of not giving antibiotics to a patient who might potentially need them, we included PSBI (mostly cases of pneumonia or ACS) in addition to CSBI.

Most children included in this study had been diagnosed by newborn screening, were completely immunized and receiving penicillin prophylaxis. We found a low rate of CSBI, with a higher proportion of PSBI (mainly pneumonia/ACS), in agreement to other studies from high-income countries $[1,3,6]$. Several studies had previously reported different predictors of bacteremia and other severe infections in patients with $\mathrm{SCD}$, including elevated CRP, procalcitonin, WBC and neutrophils, toxic appearance, vomiting and longterm CVC, similarly to our findings [2, 4, 7, 8]. IL-6 has also been recently described by our group as a marker of CSBI in these patients [5]. Other studies had also reported hypoxemia and elevated WBC or neutrophils as predictors of pneumonia or ACS [3, 9]. Since, to date, none of the above has been able to unequivocally discriminate patients with SBI as a single marker, we decided to design a risk score for the prediction of SBI combining several of them. Younger age is another traditional risk factor of SBI in patients with SCD. However, although it is well described that before the introduction of prophylactic measures younger patients presented the majority of infections and episodes of severe sepsis, there are recent studies which have found the opposite [2]. In our study, we did not find any differences in age between groups and, for that reason, age was not included in the predictive model used to design the risk score.

We designed a risk score including 3 variables (CRP, IL-6 and hypoxemia), assigning 2,1 and 1 points to each variable, respectively. An individualized score of $<1$ point ( 0 points) had the highest sensitivity and NPV, while a score of $\geq 3$ points had the highest specificity and PPV, both for CSBI and for PSBI. We divided the children in 3 groups: low risk (0 points), moderate risk (1-2 points) and high risk (3-4 points) of SBI. In our cohort, $38(48.1 \%)$ patients would have been classified as low risk, without any case of CSBI and just one of PSBI in this group (a child diagnosed with "mild ACS" because of an infiltrate in the chest X-ray without hypoxemia; he only had one day of fever and bocavirus was detected in respiratory samples). However, in the group of high risk, we found 9/9 (100\%) SBI cases, 3 of them (33.3\%) CSBI.

Based on our findings, we propose a different management according to the risk of SBI of each patient, described in Fig. 2 (excluding patients with toxic appearance and those incompletely immunized, non-adherent to penicillin prophylaxis and CVC carriers, due to their higher risk of SBI). We recommend that in patients classified in the low-risk group the use of empirical broad-spectrum antibiotics could be avoided, while those with moderate risk should receive at least one intravenous dose of a long-acting and broadspectrum antibiotic such as ceftriaxone. All these low-risk children could be managed as outpatients, with blood cultures done and close follow-up within $24 \mathrm{~h}$, as long as they do not present other complications (e.g. significant anemia or severe pain) and have the possibility of quick access to the hospital in case of clinical worsening. However, patients with high risk of SBI should be hospitalized and receive broad-spectrum antibiotics, at least until blood cultures remain negative after $48-72 \mathrm{~h}$ of incubation. According to our data, this approach would potentially prevent almost a half of antibiotic treatments and the majority of the hospital admissions.

This study has several limitations. Most importantly, the sample size is relatively small, with few cases of confirmed 
Table 1 Characteristics of patients at baseline and during febrile episodes

\begin{tabular}{|c|c|c|c|c|c|c|c|}
\hline Characteristic & Overall $(n=79)$ & Patients without & $\mathrm{SBI}(n=62)$ & $\begin{array}{l}\text { Patients with CSBI } \\
(n=4)\end{array}$ & $p$ value & $\begin{array}{l}\text { Patients with } \\
\text { CSBI or PSBI } \\
(n=17)\end{array}$ & $p$ value \\
\hline \multicolumn{8}{|c|}{ Baseline characteristics of patients } \\
\hline Age in years [m (IQR)] & $4.1(1.7-7.5)$ & $3.7(1.4-7.8)$ & & $4(1.4-6)$ & 0.613 & $5.5(3.3-6.2)$ & 0.633 \\
\hline Male $[$ no. $(\%)]$ & $62(78.5)$ & $49(79)$ & & $3(75)$ & 0.624 & $13(76.5)$ & 0.527 \\
\hline $\begin{array}{l}\text { Genotype [no. (\%)] } \\
\text { SS } \\
\text { SC } \\
\text { S } \beta \text {-thalassemia }\end{array}$ & $\begin{array}{l}68(86.1) \\
5(6.3) \\
6(7.6)\end{array}$ & $\begin{array}{l}53(85.5) \\
5(8.1) \\
4(6.5)\end{array}$ & & $\begin{array}{l}4(100) \\
0 \\
0\end{array}$ & 0.715 & $\begin{array}{l}15(88.2) \\
0 \\
2(11.8)\end{array}$ & 0.391 \\
\hline $\begin{array}{l}\text { Newborn screening } \\
{[\text { no. }(\%)]}\end{array}$ & $72(91.1)$ & $56(90.3)$ & & $4(100)$ & 0.677 & $16(94.1)$ & 0.530 \\
\hline $\begin{array}{l}\text { Parents' origin [no. } \\
(\%)] \\
\text { Africa } \\
\text { America } \\
\text { Other }\end{array}$ & $\begin{array}{l}33(41.8) \\
45(57) \\
1(1.3)\end{array}$ & $\begin{array}{l}25(40.3) \\
36(58.1) \\
1(1.6)\end{array}$ & & $\begin{array}{l}4(100) \\
0 \\
0\end{array}$ & 0.066 & $\begin{array}{l}8(47.1) \\
9(52.9) \\
0\end{array}$ & 0.786 \\
\hline $\begin{array}{l}\text { Completely immunized } \\
\text { [no. }(\%)]\end{array}$ & $70(88.6)$ & $55(88.7)$ & & $4(100)$ & 0.631 & $15(88.2)$ & 0.622 \\
\hline $\begin{array}{l}\text { Penicillin prophylaxis } \\
\text { [no. }(\%)]\end{array}$ & $76(98.7)$ & $59(98.3)$ & & $4(100)$ & 0.938 & $17(100)$ & 0.779 \\
\hline Splenectomy [no. (\%)] & $8(10.1)$ & $5(8.1)$ & & 0 & 0.724 & $3(17.6)$ & 0.229 \\
\hline $\begin{array}{l}\text { Central venous catheter } \\
\text { [no. }(\%)]\end{array}$ & $18(22.8)$ & $14(22.6)$ & & $2(50)$ & 0.245 & $4(23.5)$ & 0.583 \\
\hline $\begin{array}{l}\text { Hypertransfusional } \\
\text { regimen [no. }(\%)]\end{array}$ & $9(11.4)$ & $7(11.3)$ & & $2(50)$ & 0.087 & $2(11.8)$ & 0.622 \\
\hline $\begin{array}{l}\text { Previous hospital } \\
\text { admissions [m (IQR)] }\end{array}$ & $6(2-10.5)$ & $6.5(2-11)$ & & $3.5(2-6.5)$ & 0.382 & $6(3-9)$ & 0.914 \\
\hline \multicolumn{8}{|l|}{ Clinical presentation } \\
\hline $\begin{array}{l}\text { Days of fever [m } \\
\text { (IQR)] }\end{array}$ & $1(1-1)$ & & $1(1-1)$ & $1(1-2)$ & 0.821 & $1(1-2)$ & 0.510 \\
\hline $\begin{array}{l}\text { Max. temperature [m } \\
\text { (IQR)] }\end{array}$ & $38.8(38.4-39.1)$ & & $38.7(38.3-39)$ & $39.1(38.9-39.2)$ & 0.172 & $39(38.8-39.3)$ & 0.028 \\
\hline $\begin{array}{l}\text { Upper respiratory } \\
\text { symptoms [no. (\%)] }\end{array}$ & $49(62)$ & & $39(62.9)$ & $2(50)$ & 0.490 & $10(58.8)$ & 0.759 \\
\hline $\begin{array}{l}\text { Hemodynamic instabil- } \\
\text { ity [no. }(\%)]\end{array}$ & $2(2.5)$ & & $1(1.6)$ & $1(25)$ & 0.118 & $1(5.9)$ & 0.386 \\
\hline $\begin{array}{l}\text { Hypoxemia < } 92 \% \text { [no. } \\
\quad(\%)]\end{array}$ & $10(12.7)$ & & $2(3.2)$ & 0 & 0.882 & $8(47.1)$ & $<0.001$ \\
\hline \multicolumn{8}{|l|}{ Laboratory parameters } \\
\hline $\begin{array}{l}\text { Initial hemoglobin } \mathrm{g} / \mathrm{dl} \\
\text { [m (IQR)] }\end{array}$ & $8.5(7.5-9.5)$ & $8.6(7.6-9.7)$ & & $9(8.4-9.5)$ & 0.697 & $7.9(6.6-8.6)$ & 0.062 \\
\hline $\begin{array}{l}\text { Initial WBC } \times 10^{9} / \mathrm{L} \\
{[\mathrm{m}(\mathrm{IQR})]}\end{array}$ & $13.8(9.7-21.1)$ & $12.1(9.4-20.3)$ & & $20.7(17.6-31.4)$ & 0.049 & $18.2(15.4-22.1)$ & 0.024 \\
\hline $\begin{array}{l}\text { Initial neutrophils } \\
\times 10^{9} / \mathrm{L} \text { [m (IQR)] }\end{array}$ & $8.1(5.1-13.8)$ & $6.9(4.7-13.2)$ & & $16.8(13.9-26.7)$ & 0.012 & $13.7(8.1-14.6)$ & 0.009 \\
\hline $\begin{array}{l}\text { Initial CRP mg/dl [m } \\
\text { (IQR)] }\end{array}$ & $2(0.4-5.9)$ & $1.2(0.4-3.4)$ & & $9.6(7.8-15.1)$ & 0.004 & $7.6(5.6-11)$ & $<0.001$ \\
\hline $\begin{array}{l}\text { Max. CRP mg/dl } \\
\quad(n=56)[\mathrm{m}(\mathrm{IQR})]\end{array}$ & $4(1.1-10.1)$ & $3.1(0.8-5.3)$ & & $13.5(12.3-17.9)$ & 0.010 & $10.7(9-18.6)$ & $<0.001$ \\
\hline $\begin{array}{l}\text { Initial PCT ng/ml [m } \\
\text { (IQR)] }\end{array}$ & $0.3(0.2-0.6)$ & $0.3(0.2-0.5)$ & & $2(0.8-2.9)$ & 0.021 & $0.4(0.3-1.3)$ & 0.054 \\
\hline $\begin{array}{l}\text { Max. PCT ng/ml } \\
\quad(n=40)[\mathrm{m}(\mathrm{IQR})]\end{array}$ & $0.5(0.2-1.4)$ & $0.4(0.2-0.9)$ & & $3.1(1.8-18.9)$ & 0.049 & $0.5(0.3-1.6)$ & 0.326 \\
\hline IL-6 pg/ml [m (IQR)]* & $0.7(0.7-0.7)$ & $0.7(0.7-0.7)$ & & $163(70.4-459.5)$ & $<0.001$ & $0.7(0.7-58)$ & $<0.001$ \\
\hline Outcome & & & & & & & \\
\hline
\end{tabular}


Table 1 (continued)

\begin{tabular}{|c|c|c|c|c|c|c|}
\hline Characteristic & Overall $(n=79)$ & Patients without SBI $(n=62)$ & $\begin{array}{l}\text { Patients with CSBI } \\
(n=4)\end{array}$ & $p$ value & $\begin{array}{l}\text { Patients with } \\
\text { CSBI or PSBI } \\
(n=17)\end{array}$ & $p$ value \\
\hline $\begin{array}{l}\text { Hospital admission } \\
\text { [no. (\%)] }\end{array}$ & $64(81)$ & $47(75.8)$ & $4(100)$ & 0.347 & $17(100)$ & 0.017 \\
\hline $\begin{array}{l}\text { Antibiotic treatment } \\
{[\text { no. }(\%)]}\end{array}$ & $76(96.2)$ & $59(95.2)$ & $4(100)$ & 0.826 & 17 (100) & 0.478 \\
\hline $\begin{array}{l}\text { Need for antibiotic } \\
\text { change [no. }(\%)]\end{array}$ & $12(15.2)$ & $4(6.7)$ & $3(75)$ & 0.003 & $8(47.1)$ & $<0.001$ \\
\hline $\begin{array}{l}\text { Final diagnosis of VOC } \\
\text { [no. }(\%)]\end{array}$ & $7(8.9)$ & 7 (11.3) & 0 & 0.631 & 0 & 0.170 \\
\hline $\begin{array}{l}\text { PICU admission [no. } \\
(\%)]\end{array}$ & $3(3.8)$ & $1(1.6)$ & 0 & 0.939 & $2(11.8)$ & 0.115 \\
\hline $\begin{array}{l}\text { Total days of fever [m } \\
\text { (IQR)] }\end{array}$ & $2(1-4)$ & $2(1-3)$ & $2.5(2-4)$ & 0.304 & $3(2-6)$ & 0.007 \\
\hline $\begin{array}{l}\text { Days of admission [m } \\
\text { (IQR)] }\end{array}$ & $4(2-6)$ & $3.5(1.5-5)$ & $7.5(5.5-8.5)$ & 0.017 & $7(5-8)$ & $<0.001$ \\
\hline
\end{tabular}

All comparisons are related to the group without SBI. Variables with significant differences $(p$ value $<0.05)$ are highlighted in bold font

$S B I$ severe bacterial infection, $C S B I$ confirmed severe bacterial infection, $P S B I$ possible bacterial infection, $m$ (IQR) median (interquartile range), $M a x$. maximum value during the episode, $C R P$ C-reactive protein, $P C T$ procalcitonin, $I L-6$ interleukin $6, V O C$ vasoocclusive crisis, $P I C U$ pediatric intensive care unit

*The other cytokines analyzed did not show any significant differences

bacterial infection. However, this prospective study was carried out in a reference center for SCD in Spain and this cohort may be quite representative of children with SCD in high-income countries, in which the incidence of SBI is low. Second, ACS cases were classified as PSBI due to the difficulty of excluding a bacterial pneumonia in these cases. Finally, IL-6 may not be available in all centers although its use as a biomarker has become widespread recently due to anti-IL-6 use in SARS-CoV-2 pandemic.

In conclusion, we developed a score to estimate the risk of SBI (confirmed or possible, such as ACS) applicable to
SCD children who are completely immunized, receive adequate prophylaxis and are trained to detect warning signs of severity. This proposal could help change the current practice of administering antibiotics to all children with SCD and fever into a different strategy of management, according to the risk group of each patient. Further studies are needed to validate this score and to confirm these findings. This may result in safely minimizing the use of broad-spectrum antibiotics and hospital admissions in SCD patients at low risk of SBI. 
Table 2 Performance of the predictive model according to different cut-off values and individualized risk score of patients in our cohort

\begin{tabular}{|c|c|c|c|c|}
\hline Risk score & Sensitivity \% (95\% CI) & Specificity \% (95\% CI) & PPV \% (95\% CI) & NPV \% (95\% CI) \\
\hline \multicolumn{5}{|c|}{ Confirmed SBI } \\
\hline$\geq 1$ point & $100(39.8-100)$ & $50(40.2-63.7)$ & $\begin{array}{l}\text { PR 5\%: } 9.9(8-12.2) \\
\text { PR 10\%: } 18.8(15.5-22.7) \\
\text { PR 15\%: } 26.9(22.5-31.8)\end{array}$ & $\begin{array}{l}\text { PR 5\% } 100(88.6-100) \\
\text { PR 10\%: } 100(88.6-100) \\
\text { PR 15\%: } 100(88.6-100)\end{array}$ \\
\hline$\geq 2$ points & $100(39.8-100)$ & $57.3(45.4-68.7)$ & $\begin{array}{l}\text { PR 5\%: } 11(8.7-13.8) \\
\text { PR 10\%: } 20.7(16.7-25.3) \\
\text { PR 15\%: } 29.3(24.1-35)\end{array}$ & $\begin{array}{l}\text { PR 5\% } 100(89.8-100) \\
\text { PR 10\%: } 100(89.8-100) \\
\text { PR 15\%: } 100(89.8-100)\end{array}$ \\
\hline$\geq 3$ points & 75 (19.4-99.4) & $92(83.4-97)$ & $\begin{array}{l}\text { PR 5\%: } 33(16-56.1) \\
\text { PR 10\%: } 51(28.6-73) \\
\text { PR 15\%: } 62.3(38.9-81.1)\end{array}$ & $\begin{array}{l}\text { PR 5\% 98.6 (92.7-99.7) } \\
\text { PR 10\%: } 97.1(85.8-99.5) \\
\text { PR 15\%: } 95.4(79.2-99.1)\end{array}$ \\
\hline \multicolumn{5}{|c|}{ Confirmed or possible SBI } \\
\hline$\geq 1$ point & $94.1(71.3-99.9)$ & $61.3(48.1-73.4)$ & $\begin{array}{l}\text { PR 5\%: } 11.3(8.4-15.2) \\
\text { PR 10\%: } 21.3(16.2-27.4) \\
\text { PR 15\%: } 30(23.5-37.5)\end{array}$ & $\begin{array}{l}\text { PR 5\% 99.5 (96.7-99.9) } \\
\text { PR 10\%: } 98.9(93.3-99.8) \\
\text { PR 15\%: } 98.3(89.7-99.8)\end{array}$ \\
\hline$\geq 2$ points & $82.4(56.6-96.2)$ & $64.5(51.3-76.3)$ & $\begin{array}{l}\text { PR 5\% } 10.9(7.6-15.4) \\
\text { PR 10\%: } 20.5(14.7-27.8) \\
\text { PR 15\%: } 29.1(21.5-38)\end{array}$ & $\begin{array}{l}\text { PR 5\% 98.6 (96.1-99.5) } \\
\text { PR 10\%: } 97.1(92.1-98.9) \\
\text { PR 15\%: } 95.4 \text { (87.9-98.3) }\end{array}$ \\
\hline$\geq 3$ points & $52.9(27.8-77)$ & $100(94.2-100)$ & $\begin{array}{l}\text { PR 5\% } 100(62.9-100) \\
\text { PR 10\%: } 100(62.9-100) \\
\text { PR 15\%: } 100(62.9-100)\end{array}$ & $\begin{array}{l}\text { PR 5\% } 97.6(96.1-98.5) \\
\text { PR 10\%: } 95(92-96.9) \\
\text { PR 15\%: } 92.3(87.9-95.2)\end{array}$ \\
\hline \multicolumn{5}{|c|}{ Individualized risk score of patients in our cohort } \\
\hline & & No. of patients & Patients with CSBI & $\begin{array}{l}\text { Patients with } \\
\text { CSBI or } \\
\text { PSBI }\end{array}$ \\
\hline Low risk $(0$ & & 38 & 0 & $1^{\mathrm{a}}(2.6 \%)$ \\
\hline Moderate ris & points) & 32 & $1(3.1 \%)$ & $7(21.9 \%)$ \\
\hline High risk $(3$ & tts) & 9 & $3(33.3 \%)$ & $9(100 \%)$ \\
\hline
\end{tabular}

$S B I$ severe bacterial infection, $C S B I$ confirmed severe bacterial infection, $P S B I$ possible bacterial infection, $C I$ Confidence interval, $P P V$ Positive predictive value, $N P V$ Negative predictive value, $P R$ Prevalence rate

apatient diagnosed with "mild acute chest syndrome"

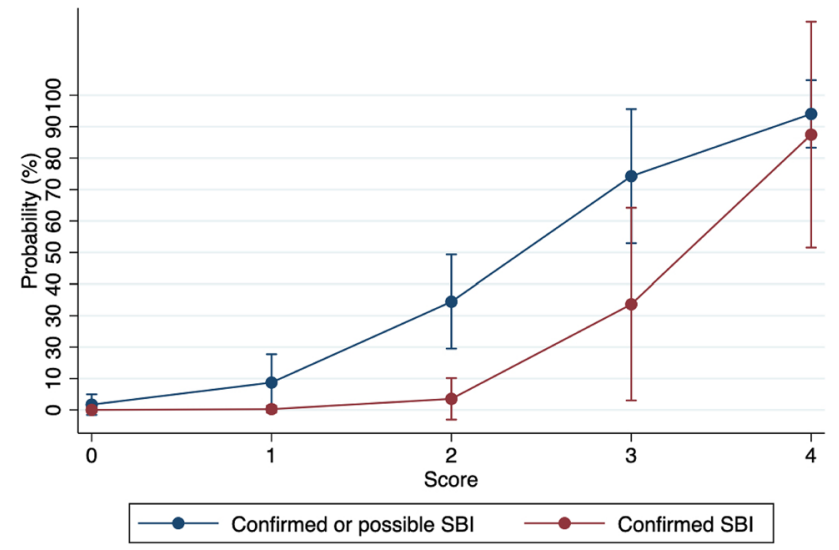

Fig. 2 Probability of SBI according to the risk score

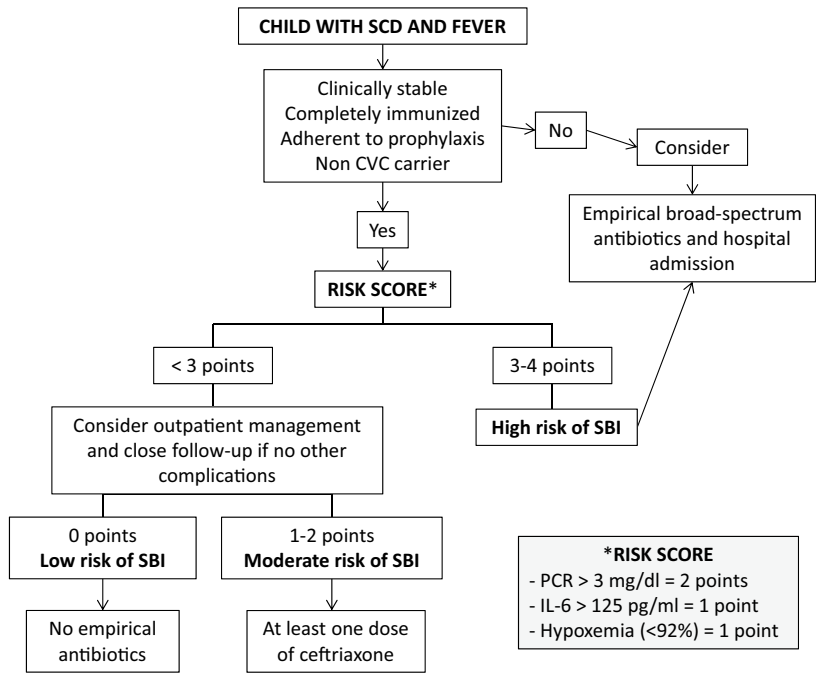

Fig. 3 Proposal for the management of children with SCD and fever according to their risk score 
Supplementary Information The online version contains supplementary material available at https://doi.org/10.1007/s15010-021-01702-w.

Acknowledgements We thank HGUGM nurses for their help in collecting samples and the Spanish HIV HGM Biobank for storing and processing blood samples for cytokine analysis. We also thank Ana María Rincón-López, official translator, for her careful review of the manuscript.

Other collaborators of F-DREP Study Group: Begoña Santiago García $^{1}$, Alicia Hernanz Lobo ${ }^{1}$, Eduardo Bardón Cancho ${ }^{4}$, Carmen Garrido Colino ${ }^{4}$, Jorge Huerta Aragonés ${ }^{4}$, Cristina Mata Fernández ${ }^{4}$, Concepción Míguez Navarro ${ }^{5}$, Andrea Mora Capín ${ }^{5}$, Rafael Marañón Pardillo $^{5}$, Arístides Rivas García ${ }^{5}$, Paula Vázquez López ${ }^{5}$, José Luis Jiménez Fuentes ${ }^{7}$, Maria Ángeles Muñoz Fernández ${ }^{7}$, Rosario Zamarro Arranz ${ }^{8}$. Affiliations: ${ }^{1}$ Department of Pediatrics. Pediatric Infectious Diseases Unit, Hospital General Universitario Gregorio Marañón, Instituto de Investigación Sanitaria Gregorio Marañón (IiSGM), Madrid, Spain; ${ }^{2} \mathrm{PhD}$ Program in Medicine, Universidad Complutense de Madrid, Madrid, Spain; ${ }^{3}$ Universidad Complutense de Madrid, Madrid, Spain; ${ }^{4}$ Instituto de Investigación Sanitaria Gregorio Marañón (IiSGM), Madrid, Spain; ${ }^{5}$ Department of Pediatrics. Pediatric Hematology and Oncology Unit, Hospital General Universitario Gregorio Marañón, Madrid, Spain; ${ }^{6}$ Department of Pediatrics. Pediatric Emergency Unit, Hospital General Universitario Gregorio Marañón, Madrid, Spain; ${ }^{7}$ Immunology Section, Laboratorio InmunoBiología Molecular, Instituto Investigación Sanitaria Gregorio Marañón, Hospital General Universitario Gregorio Marañón, Spanish HIV HGM BioBank, Madrid, Spain; ${ }^{8}$ Health educator of parents and children with sickle cell disease. Nurse in Hospital General Universitario Gregorio Marañón, Madrid, Spain

Author contributions All authors contributed to the study conception and design. Material preparation, data collection and analysis were performed by EMR-L, DA-A and EDM. The first draft of the manuscript was written by EMR-L and all authors commented on previous versions of the manuscript. All authors read and approved the final manuscript.

Funding This work was supported by an unrestricted grant award from the European Society for Pediatric Infectious Diseases (ESPID Small Grant 2017). The sponsor did not participate in the study design or interpretation of the results.

\section{Declarations}

Conflict of interest The authors have no conflicts of interest or financial relationships relevant to this article to disclose.

Availability of data and material The data that support the findings of this study are available on request from the corresponding author. The data are not publicly available due to ethical restrictions.

Code availability Not applicable.

Ethics approval This study was performed in line with the principles of the Declaration of Helsinki. Approval was granted by the Ethics Committee of the Hospital General Universitario Gregorio Marañón (CEIm HGUGM) in Madrid, Spain.
Consent to participate Informed consent was obtained from parents or legal guardians of all patients included in the study.

Consent for publication Parents or legal guardians of patients signed informed consent regarding publishing their data.

\section{References}

1. Bala N, Chao J, John D, Sinert R. Prevalence of bacteremia in febrile patients with sickle cell disease. Pediatr Emerg Care. 2019; Publish Ah:1-6. https://doi.org/10.1097/pec.0000000000 001944.

2. Chang TP, Kriengsoontorkij W, Chan LS, Wang VJ. Predictors for bacteremia in febrile sickle cell disease children in the post7-valent pneumococcal conjugate vaccine era. J Pediatr Hematol Oncol. 2013;35:377-82. https://doi.org/10.1097/MPH.0b013 e31828ac9e2.

3. Chang TP, Kriengsoontorkij W, Chan LS, Wang VJ. Clinical factors and incidence of acute chest syndrome or pneumonia among children with sickle cell disease presenting with a fever: a 17-year review. Pediatr Emerg Care. 2013;29:781-6. https://doi.org/10. 1097/PEC.0b013e31829829f7.

4. Rincón-López EM, Navarro Gómez ML, Hernández-Sampelayo Matos T, et al. Low-risk factors for severe bacterial infection and acute chest syndrome in children with sickle cell disease. Pediatr Blood Cancer. 2019;66:1-7. https://doi.org/10.1002/pbc.27667.

5. Cela, E, Ruiz, A, Cervera Á. Enfermedad de células falciformes. Guía de práctica clínica de la Sociedad Española de Hematología y Oncología Pediátricas. CeGe, editor. 2019. http://www.sehop. org/wp-content/uploads/2019/03/Guía-SEHOP-Falciforme-2019. pdf. Accessed 15 June 2021.

6. Rincón-López EM, Navarro Gómez ML, Hernández-Sampelayo Matos T, et al. Interleukin 6 as a marker of severe bacterial infection in children with sickle cell disease and fever: a case-control study. BMC Infect Dis. 2021;21:741. https://doi.org/10.1186/ s12879-021-06470-4.

7. Bansil NH, Kim TY, Tieu L, Barcega B. Incidence of serious bacterial infections in febrile children with sickle cell disease. Clin Pediatr (Phila). 2013;52:661-6. https://doi.org/10.1177/ 0009922813488645.

8. Morrissey BJ, Bycroft TP, Almossawi O, Wilkey OB, Daniels JG. Incidence and predictors of bacterial infection in febrile children with sickle cell disease. Hemoglobin. 2015;39:316-9. https://doi. org/10.3109/03630269.2015.1065419.

9. Elenga N, Placide L, Cuadro-alvarez E, et al. Does procalcitonin predict bacterial infection in febrile children with sickle cell disease? Indian J Pediatr. 2019;86:95-6. https://doi.org/10.1007/ s12098-018-2717-x.

10. Eisenbrown K, Nimmer M, Ellison AM, Simpson P, Brousseau DC. Which febrile children with sickle cell disease need a chest X-ray? Acad Emerg Med. 2016;23:1248-56. https://doi.org/10. 1111/acem.13048. 